Check for updates

Cite this: J. Mater. Chem. B, 2020 8, 9295

Received 28th June 2020,

Accepted 31st August 2020

DOI: $10.1039 / d 0 t b 01598 a$

rsc.li/materials-b

\section{Two-dimensional iron MOF nanosheet as a highly efficient nanozyme for glucose biosensing $\dagger$}

\author{
Ai Yuan, Yuwan Lu, Xiaodan Zhang, Qiumeng Chen and Yuming Huang (D) *
}

Two-dimensional (2D) nanomaterials are attractive in catalysis due to their rich accessible active sites. Iron-based metal organic frameworks (MOFs) are promising nanozymes because of their iron center and pore structure. However, it is challenging to obtain iron-based 2D MOF nanozymes due to the coordinated form of iron. Herein, we report a cation substitution strategy to transform an easily obtained $\mathrm{Cu}(\mathrm{HBTC})\left(\mathrm{H}_{2} \mathrm{O}\right)_{3}$ (represented as $\mathrm{Cu}(\mathrm{HBTC})-1$, the product of only two carboxylate groups in 1,3,5-benzenetricarboxylic acid ( $\mathrm{H}_{3} \mathrm{BTC}$ ) ligands linked by $\mathrm{Cu}$ ions) nanosheet into a 2D Fe-BTC nanosheet, which was characterized by SEM (scanning electron microscopy), AFM (atomic force microscopy), XPS (X-ray photoelectron spectroscopy), FT-IR (Fourier transform infrared spectroscopy), and XRD (X-ray diffraction). The 2D Fe-BTC nanosheet can catalyze TMB (3,3',5,5'-tetramethylbenzidine) oxidation by $\mathrm{H}_{2} \mathrm{O}_{2}$, showing its intrinsic peroxidase mimetic characteristic. The catalytic performance of 2D Fe-BTC was superior to those of its template $\mathrm{Cu}(\mathrm{HBTC})-1$ nanosheet and 3D MIL-100(Fe). Their catalytic activities follow the order of 2D Fe-BTC $>$ MIL-100(Fe) $>2$ D Cu(HBTC) -1 . The peroxidase-like activity of 2D Fe-BTC is 77 times that of its template $\mathrm{Cu}(\mathrm{HBTC})-1$, and 2.2 times that of MIL-100(Fe), a well known 3D crystalline form of iron trimesates. The $K_{m}$ values of $2 \mathrm{D}$ Fe-BTC for TMB and $\mathrm{H}_{2} \mathrm{O}_{2}$ were $0.2610 \mathrm{mM}$ and $0.0334 \mathrm{mM}$, which were 1.6 and 1.9-fold lower than those of 3D MIL-100(Fe), respectively. The TMB oxidation rate and $\mathrm{H}_{2} \mathrm{O}_{2}$ reduction rate at unit mass concentration of the catalyst $\left(K_{w}\right)$ for 2D Fe-BTC were 2.7-72.3 and 1.5-37.9 times those for the previously reported 3D MOF nanozymes, respectively. In terms of the excellent peroxidase mimetic characteristic of 2D Fe-BTC, a sensitive and selective colorimetric biosensing platform for hydrogen peroxide and glucose was developed. The linear ranges are 0.04-30 $\mu \mathrm{M}$ and 0.04-20 $\mu \mathrm{M}$ for $\mathrm{H}_{2} \mathrm{O}_{2}$ and glucose, with a low detection limit of $36 \mathrm{nM}$ and $39 \mathrm{nM}$, respectively. The assay was satisfactorily applied to glucose determination in biological matrices.

\section{Introduction}

Metal organic frameworks (MOFs) are porous crystalline materials, which are produced by self-assembly of polydentate organic ligands bridged with metal nodes. The unique microstructure gives MOFs attractive characteristics, such as high specific surface area, adjustable porosity and cavities. Therefore, they have been widely used in various fields, such as small-molecule sensing, gas storage, and catalysis. ${ }^{1}$ In particular, great progress has been made in using MOFs as catalysts to mimic enzymatic activities. ${ }^{2-7}$ For example, Zhou's group demonstrated effective peroxidase-like activity of MOF PCN222 with Fe-based tetrakis(4-carboxyphenyl)porphyrin (TCPP) ligands capable of catalyzing the oxidation of several substrates, ${ }^{2}$ while those with other metal-based (manganese,

College of Chemistry and Chemical Engineering, Southwest University,

Chongqing 400715, China. E-mail: ymhuang@swu.edu.cn

$\dagger$ Electronic supplementary information (ESI) available. See DOI: 10.1039/d0tb01598a cobalt, nickel, copper, and zinc) TCPP ligands exhibited significantly lower peroxidase-like activity. Ma's group demonstrated the interesting peroxidase mimetic function of a highly stable mesoporous metal-metalloporphyrin framework-6 (MMPF-6) that was synthesized through self-assembly of iron-based ligands and $\mathrm{Zr}_{6} \mathrm{O}_{8}\left(\mathrm{CO}_{2}\right)_{8}\left(\mathrm{H}_{2} \mathrm{O}\right)_{8}$ secondary building units (SBUs). ${ }^{3 a}$ Their excellent catalytic performance as peroxidase is attributed to the high density of the porphyrin (heme-like) active centers in PCN-222(Fe) and MMPF-6. In addition, other iron-based MOFs, such as MIL-53(Fe), ${ }^{4}$ Fe-NH ${ }_{2}-\mathrm{MIL}-88,{ }^{5}$ MIL-68(Fe), ${ }^{6}$ and MIL-100(Fe), ${ }^{7}$ have also been reported to possess mimic enzyme activity because of their efficient catalytic decomposition of hydrogen peroxide to produce reactive oxygen species, and they can be used as nanozymes for bioanalytical applications. However, these MOF nanozymes are mainly 3D bulk MOF crystals. The intrinsic narrow pore window of MOFs makes the diffusion rate of the substrate limited, and thus reduces the accessible active sites in 3D bulk crystals and restricts the catalytic performance of MOF nanozymes. 
Two-dimensional (2D) nanomaterials have received considerable interest because of their uncommon structure, like large specific surface area, ultrathin thickness and high surface-tovolume ratios. ${ }^{8-10}$ Unlike bulk crystals where most of the active sites are hidden in the framework, thin 2D nanomaterials with large surface area expose highly accessible active sites on their surface. ${ }^{11 a}$ This leads to lower mass transfer resistance, a smaller diffusion barrier and great potential for application in catalysis. Metal organic framework nanosheets, a new member of ultrathin 2D nanomaterials that combine the advantages of 2D nanomaterials with MOF crystals, can be used to prepare nanozymes with excellent performance and have received increasing interest in recent years. ${ }^{8,11 a, b, 12}$ However, up to now, the reported MOF nanosheets are limited to $\mathrm{Zn}, \mathrm{Cu}$, or Co-based metal centers due to the specific SBU structure. ${ }^{8,12-15}$ Interestingly, Zhang's group designed a series of ultrathin $2 \mathrm{D}$ bimetallic MOF nanosheets via self-assembly of $\mathrm{Zn}, \mathrm{Cu}$, or Co as metal nodes and Fe-based TCPP as ligands, ${ }^{12}$ and investigated their enzyme-like property. Most recently, Wei's group reported interesting findings of phosphate-responsive 2D Zn-TCPP(Fe) MOF nanozymes with high performance of peroxidase-like activity for discriminating phosphates ${ }^{16 a}$ and for a colorimetric alkaline phosphatase activity assay. ${ }^{16 b}$ However, there is still a lack of iron-based MOF nanosheets with high enzyme-like activity and it is necessary to improve the synthesis method to synthesize high-quality 2D-MOF nanosheets. ${ }^{10 a}$

Herein, based on a multivalent cation substitution strategy, ${ }^{17}$ we successfully prepared 2D iron-based MOF nanosheets and investigated their enzymatic mimetic property. As Fig. 1 shows, 2D Cu(HBTC)-1 nanosheets were prepared and used as a template, and then $\mathrm{Fe}^{3+}$ ions were introduced to prepare 2D Fe-BTC MOF nanosheets through cation exchange. The resultant Fe-BTC nanosheet displays 77 times the peroxidase-like activity of its template $\mathrm{Cu}$ (HBTC)-1 nanosheet, and 2.2 times that of MIL-100(Fe), a well known 3D crystalline form of iron trimesates. The kinetic parameters of the Fe-BTC nanosheet surpass those of the reported 3D MOF nanozymes. The result demonstrates the outstanding peroxidase mimetic characteristic of the Fe-BTC nanosheet. In terms of these outcomes, simple and sensitive detection of $\mathrm{H}_{2} \mathrm{O}_{2}$ and glucose could be achieved.

\section{Experimental section}

\subsection{Reagents and instrumentation}

The detailed reagents and instrumentation used in the work are provided in the ESI. $\dagger$

\subsection{Synthesis of MIL-100(Fe), Cu(HBTC)-1 and 2D Fe-BTC MOFs}

To prepare MIL-100(Fe), we took $3.6 \mathrm{mmol} \mathrm{Fe}\left(\mathrm{NO}_{3}\right)_{3} \cdot 9 \mathrm{H}_{2} \mathrm{O}$ and put it into $3.6 \mathrm{~mL}$ of water, followed by addition of $2.4 \mathrm{mmol}$ $\mathrm{H}_{3}$ BTC (1,3,5-benzenetricarboxylic acid). After stirring for $60 \mathrm{~min}$ at room temperature, the mixture was transferred to an autoclave that was heated at $160{ }^{\circ} \mathrm{C}$ for $12 \mathrm{~h}$.

To prepare cubic $\mathrm{Cu}_{2} \mathrm{O}$, we took $0.0134 \mathrm{~g} \mathrm{CuCl}_{2}$ and $0.1 \mathrm{~g} \mathrm{PVP}$ (polyvinylpyrrolidone) and put them into $40 \mathrm{~mL}$ of water, followed by stirring for $5 \mathrm{~min}$, and then $2.5 \mathrm{~mL}$ of $0.2 \mathrm{M} \mathrm{NaOH}$ was added slowly. Just 5 min after all $\mathrm{NaOH}$ was added, $2.5 \mathrm{~mL}$ of $0.1 \mathrm{M}$ ascorbic acid was added dropwise into the solution, followed by continuous stirring at room temperature for $5 \mathrm{~min}$. The cubic $\mathrm{Cu}_{2} \mathrm{O}$ nanoparticles were obtained by centrifuging and washing the solid with ethanol twice. Finally, the obtained cubic $\mathrm{Cu}_{2} \mathrm{O}$ nanoparticles were re-suspended into $10 \mathrm{~mL}$ of $95 \%$ ethanol.

To prepare $\mathrm{Cu}(\mathrm{HBTC})-1$, we took $0.4 \mathrm{~g}$ PVP and put it into

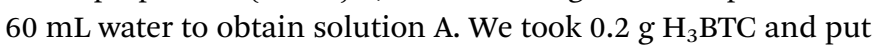
it into $4 \mathrm{~mL}$ ethanol to get solution $\mathrm{B}$. We mixed solution $\mathrm{A}$ and solution $\mathrm{B}$ under stirring to get a white mixed solution, followed by addition of $10 \mathrm{~mL}$ of $\mathrm{Cu}_{2} \mathrm{O}$ suspension in ethanol. After $16 \mathrm{~h}$ stirring, the solid product was separated by centrifugation, and was rinsed two times using $\mathrm{CH}_{3} \mathrm{CH}_{2} \mathrm{OH} / \mathrm{H}_{2} \mathrm{O}$ and vacuum-dried at $25{ }^{\circ} \mathrm{C}$ for $24 \mathrm{~h}$.

To synthesize 2D Fe-BTC, we took $10 \mathrm{mg}$ of $\mathrm{Cu}(\mathrm{HBTC})-1$ and put it into $20 \mathrm{~mL}$ water, followed by ultrasound treatment for $5 \mathrm{~min}$. Next, we added $30 \mathrm{mg}$ of $\mathrm{FeCl}_{3} \cdot 6 \mathrm{H}_{2} \mathrm{O}$ into the mixture. After $3 \mathrm{~h}$ stirring, the solid 2D Fe-BTC product was separated by centrifugation and cleaned three times with ethanol/water, and vacuum-dried at $60{ }^{\circ} \mathrm{C}$ for $8 \mathrm{~h}$. The vacuum dried solid was utilized to prepare a $2 \mathrm{D}$ Fe-BTC suspension $\left(100 \mathrm{mg} \mathrm{L}^{-1}\right)$ by dispersing $1 \mathrm{mg}$ of the dried solid into $10 \mathrm{~mL}$ of deionized water.
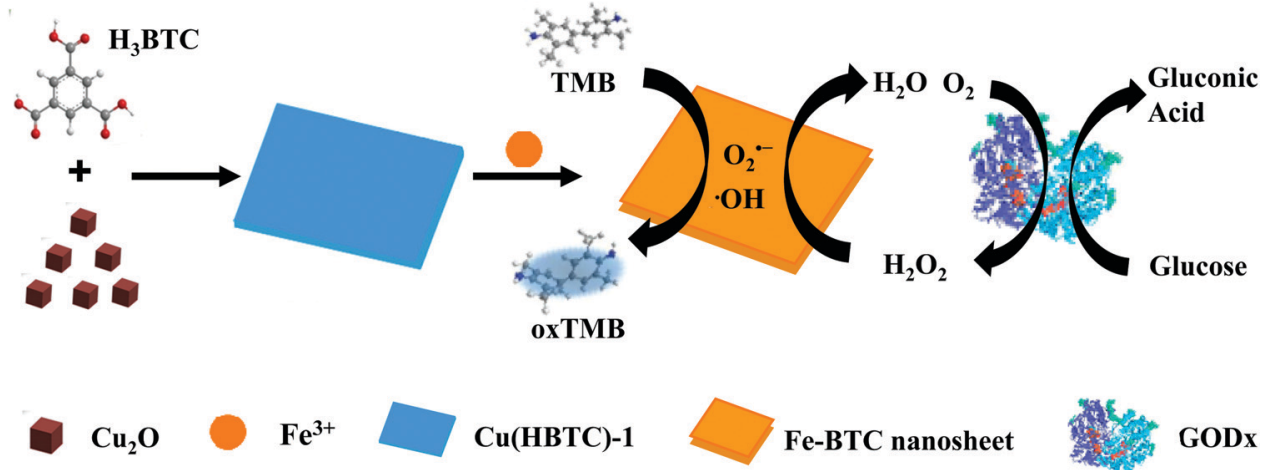

Fe-BTC nanosheet

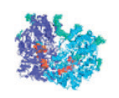

GODx

Fig. 1 Schematic of the 2D Fe-BTC preparation and its use in glucose sensing. 


\subsection{Evaluation of the peroxidase mimetic activity of $2 \mathrm{D}$ Fe-BTC}

In order to assess the peroxidase mimetic activity of $2 \mathrm{D} \mathrm{Fe}-\mathrm{BTC}$, we took an $\mathrm{H}_{2} \mathrm{O}_{2}$ solution, TMB solution and 2D Fe-BTC suspension, put them into a test tube and made them up to $5.0 \mathrm{~mL}$ with $0.2 \mathrm{M} \mathrm{NaAc-HAc}$ buffer $(\mathrm{pH}$ 3.5). The final concentrations of the $\mathrm{H}_{2} \mathrm{O}_{2}$ solution, TMB solution and 2D Fe-BTC suspension were $0.1 \mathrm{mM}, 0.1 \mathrm{mM}$, and $10 \mathrm{mg} \mathrm{L}^{-1}$, respectively. The mixed solution was incubated at $45{ }^{\circ} \mathrm{C}$ for $15 \mathrm{~min}$, and then moved to a quartz cell for subsequent UV-vis measurements.

\subsection{Steady-state kinetic analysis}

The kinetic experiment was carried out by measuring the absorbance variance at $652 \mathrm{~nm}$ within $5 \mathrm{~min}$. The experiment was performed under the optimized conditions by changing the $\mathrm{H}_{2} \mathrm{O}_{2}$ concentration at a fixed TMB concentration $(0.1 \mathrm{mM})$ or vice versa $\left(0.08 \mathrm{mM} \mathrm{H}_{2} \mathrm{O}_{2}\right)$. The kinetic parameters were determined by the following equation:

$$
v=V_{\max }[\mathrm{S}] /\left(K_{\mathrm{m}}+[\mathrm{S}]\right)
$$

where $v, V_{\max },[\mathrm{S}]$ and $K_{\mathrm{m}}$ are the initial velocity, maximal reaction velocity, substrate concentration and Michaelis constant, respectively.

\subsection{Glucose determination in biological samples}

Glucose detection in real serum samples involves a two-stage procedure, namely, glucose standard curve construction and the determination of the glucose content in the actual sample. The detailed procedures for constructing the glucose standard curve, treating the serum samples, and determining the glucose content are given in the ESI. $\dagger$

\section{Results and discussion}

\subsection{Characterization}

2D Cu(HBTC)-1 was prepared by self-assembly of trimesic acid as organic ligands bridged with copper as metal nodes. As displayed in Fig. 2a, Cu(HBTC)-1 exhibits a sheet-like morphology with a smooth surface, indicating successful preparation of two-dimensional structure precursors. The nanosheet structure was also confirmed by AFM characterization (Fig. S1a, ESI $\dagger$ ). After introducing $\mathrm{Fe}^{3+}$ ions into the $\mathrm{Cu}(\mathrm{HBTC})-1$ precursor and stirring for $3 \mathrm{~h}, \mathrm{Cu}(\mathrm{HBTC})-1$ was converted to Fe-BTC, which inherited the $2 \mathrm{D}$ structure of the $\mathrm{Cu}(\mathrm{HBTC})-1$ precursor
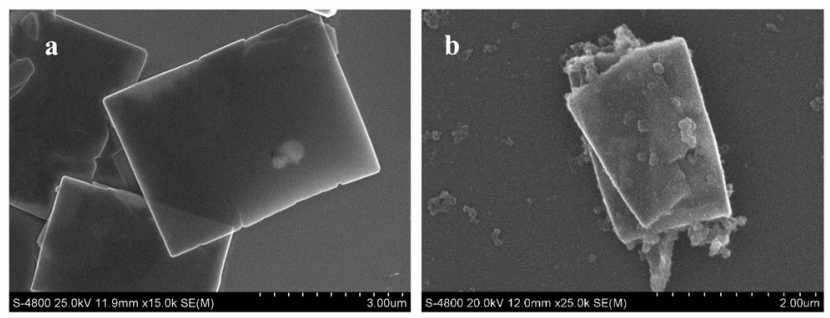

Fig. 2 (a) SEM image of $\mathrm{Cu}(\mathrm{HBTC})$-1. (b) SEM image of 2D Fe-BTC. with a rough surface (Fig. 2b). The size of Fe-BTC was about $2.6 \mu \mathrm{m} \times 2.1 \mu \mathrm{m}$ (length $\times$ width, Fig. $2 \mathrm{~b}$ and Fig. S1c, d, ESI $\dagger$ ). AFM characterization shows that the average thickness of the 2D Fe-BTC nanosheets was about $77 \mathrm{~nm}$ (Fig. S1b, ESI $\dagger$ ). However, a few stacked and some smaller Fe-BTC nanosheets can also be found (Fig. 2b and Fig. S1c, d, ESI $\dagger$ ).

The characteristic XRD diffraction peaks of $\mathrm{Cu}$ (HBTC)-1 (Fig. 3a) are similar to a previous report, ${ }^{18}$ confirming successful formation of $\mathrm{Cu}$ (HBTC)-1 through $\mathrm{Cu}_{2} \mathrm{O}$ and $\mathrm{H}_{3}$ BTC. After reaction with $\mathrm{Fe}^{3+}$ ions, the characteristic peaks in the XRD pattern of $\mathrm{Cu}$ (HBTC)-1 disappear, while some new peaks at a $2 \theta$ of $18.95^{\circ}, 23.45^{\circ}, 28.2^{\circ}$, and $33.5^{\circ}$ appear (Fig. 3a). They can be assigned to characteristic peaks of Basolite F300 (commercial Fe-BTC). ${ }^{19}$ This indicates that 2D Cu(HBTC)-1 has been transformed to 2D Fe-BTC.

The FT-IR spectra of the $\mathrm{Cu}$ (HBTC)-1 nanosheet display peaks at $1710 \mathrm{~cm}^{-1}$ and $1245 \mathrm{~cm}^{-1}$ (Fig. 3b), assigned to the $\mathrm{C}=\mathrm{O}$ and $\mathrm{C}-\mathrm{OH}$ combination bands of a carboxylic acid. $^{20}$ The two bands at $1710 \mathrm{~cm}^{-1}$ and $1245 \mathrm{~cm}^{-1}$ in $2 \mathrm{D}$ Fe-BTC are somewhat weak relative to those in $\mathrm{Cu}$ (HBTC)-1, probably due to the different coordination ability of $\mathrm{H}_{3} \mathrm{BTC}$ ligands with $\mathrm{Fe}^{3+}$ and $\mathrm{Cu}^{2+}$ in the 2D MOF structure. The peaks at $721 \mathrm{~cm}^{-1}$ and $480 \mathrm{~cm}^{-1}$ belong to stretching and bending of $\mathrm{Cu}-\mathrm{O}$ bonds in $\mathrm{Cu}(\mathrm{HBTC})-1,{ }^{21}$ while that at $480 \mathrm{~cm}^{-1}$ corresponds to the stretching $\mathrm{Fe}-\mathrm{O}$ vibration in Fe-BTC. ${ }^{22}$ The result suggested the successful transformation of $\mathrm{Cu}(\mathrm{HBTC})-1$ into 2D Fe-BTC.

The XPS spectrum of 2D Fe-BTC further clarified the composition and surface information. Comparing the XPS spectrum of $\mathrm{Cu}$ (HBTC)-1 with that of 2D Fe-BTC in Fig. 3c, the Fe 2p peak appeared in Fe-BTC, while that of $\mathrm{Cu} 2 \mathrm{p}$ disappeared. Table S1 (ESI $\dagger$ ) shows that the atomic ratios of $\mathrm{C}, \mathrm{O}$, and $\mathrm{Cu}$ in $2 \mathrm{D}$ $\mathrm{Cu}$ (HBTC)-1 are $48.31 \%, 48.21 \%$, and $3.47 \%$, respectively. The atomic ratios of $\mathrm{C}, \mathrm{O}$, and $\mathrm{Fe}$ in $2 \mathrm{D}$ Fe-BTC are $41.94 \%$, $54.93 \%$, and $3.13 \%$, respectively. Fig. 3d shows that the characteristic XPS peak in the $\mathrm{Cu} 2 \mathrm{p}_{3 / 2}$ region is observed at $934.5 \mathrm{eV}$, together with two shake-up satellites. This indicates the presence of divalent $\mathrm{Cu}(\mathrm{II})$ species. ${ }^{18 a}$ The high-resolution Fe 2p spectrum displays two peaks at $712.2 \mathrm{eV}$ and $725.8 \mathrm{eV}$, with a satellite peak at $717.8 \mathrm{eV}$ (Fig. 3e). They are attributed to Fe $2 \mathrm{p}_{3 / 2}$ and $\mathrm{Fe} 2 \mathrm{p}_{1 / 2}$ of $\mathrm{Fe}^{3+},{ }^{18 b}$ indicating that iron is in the trivalent form in $2 \mathrm{D}$ Fe-BTC. Fig. 3f shows that the peak positions of the $\mathrm{C}-\mathrm{O}-\mathrm{Cu}$ bond in $\mathrm{Cu}(\mathrm{HBTC})-1$ and $\mathrm{C}-\mathrm{O}-\mathrm{Fe}$ bond in 2D Fe-BTC were 532.20 and $532.02 \mathrm{eV}$, respectively. The binding energy of the $\mathrm{C}-\mathrm{O}-\mathrm{Cu}$ bond has a positive shift ( $\sim 0.18 \mathrm{eV}$ ) compared to the $\mathrm{C}-\mathrm{O}-\mathrm{Fe}$ bond (Fig. $3 \mathrm{f}$ ). The small shift in $\mathrm{O}$ 1s XPS indicates the successful transformation of the C$\mathrm{O}-\mathrm{Cu}$ bond in $\mathrm{Cu}$ (HBTC)-1 to the $\mathrm{C}-\mathrm{O}-\mathrm{Fe}$ bond in Fe-BTC through the cation substitution strategy. ${ }^{17}$ However, it should be indicated that the $\mathrm{O}$ 1s peak (Fig. S2, see the ESI $\dagger$ ) in the physically mixed Fe added to $\mathrm{Cu}$ (HBTC)-1 is the same as that of $\mathrm{Cu}$ (HBTC)-1, indicating that Fe-BTC cannot be formed through physical mixing.

To sum up, the characterization results from XRD, FT-IR spectra and XPS indicate successful transformation of $\mathrm{Cu}$ (HBTC)-1 to $2 \mathrm{D}$ Fe-BTC. The cation exchange also is confirmed by SEM-EDS (energy dispersive spectroscopy) elemental mapping, which shows the presence of iron element on the nanosheets (Fig. S3, ESI $\dagger$ ). 

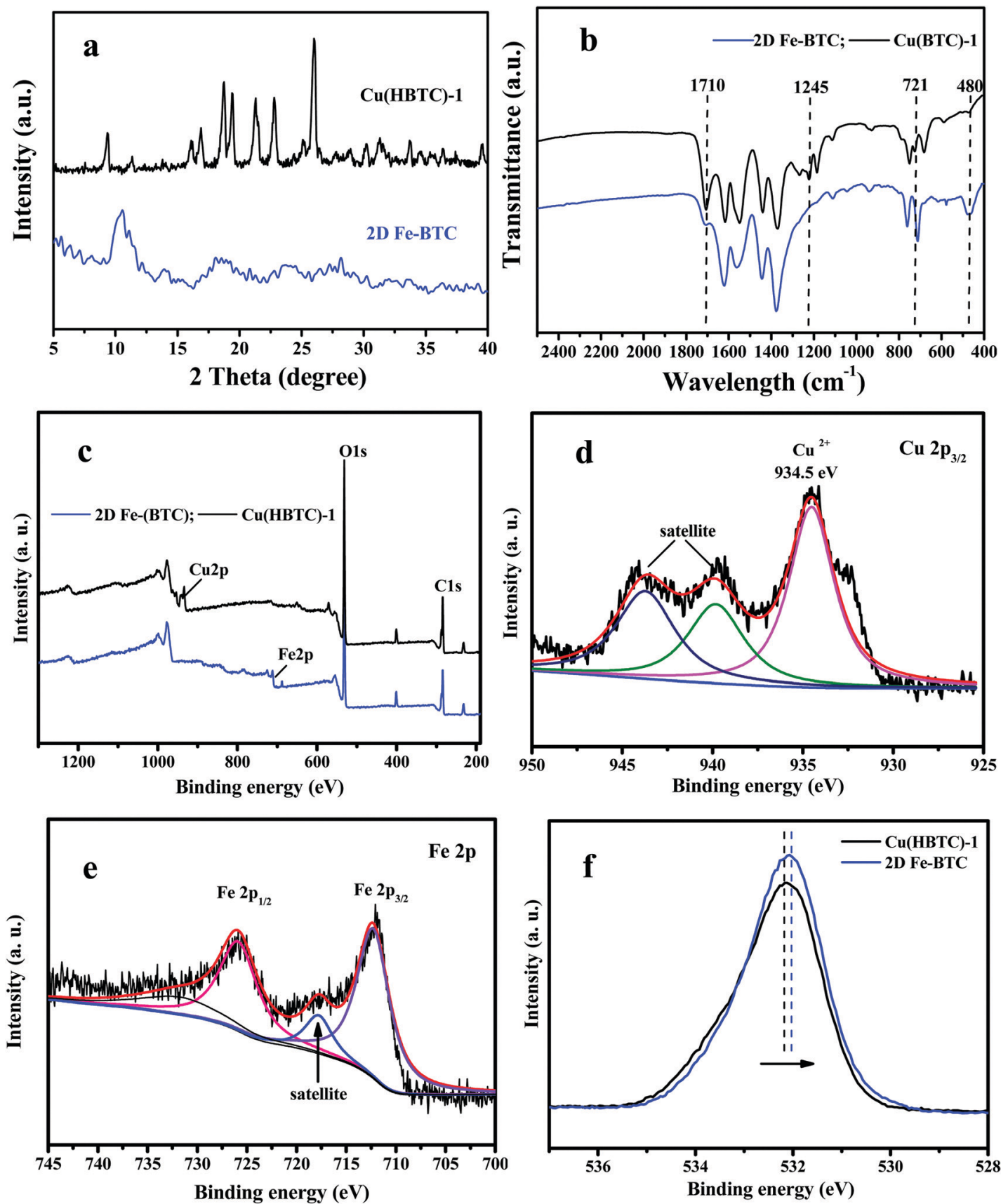

Fig. 3 (a) XRD patterns of $\mathrm{Cu}(\mathrm{HBTC})-1$ and 2D Fe-BTC. (b) The FT-IR spectra of $\mathrm{Cu}(\mathrm{HBTC})-1$ and 2D Fe-BTC. (c) The XPS spectra of Cu(HBTC)-1 and 2D Fe-BTC. (d) XPS Cu 2p peaks of Cu(HBTC)-1. (e) XPS Fe 2p peaks of 2D Fe-BTC. (f) XPS O 1s peaks of Cu(HBTC)-1 and 2D Fe-BTC.

\subsection{The peroxidase mimetic activity of $2 \mathrm{D}$ Fe-BTC}

TMB was utilized as a peroxidase mimic substrate to assess the catalytic performance of $2 \mathrm{D}$ Fe-BTC. Fig. 4 a reveals that the introduction of $2 \mathrm{D}$ Fe-BTC into the $\mathrm{H}_{2} \mathrm{O}_{2} / \mathrm{TMB}$ system caused significant absorption at $652 \mathrm{~nm}\left(A_{652}\right)$, while no obvious $A_{652}$ was observed when $\mathrm{H}_{2} \mathrm{O}_{2}$ or 2D Fe-BTC was introduced into TMB solution. The result confirms the intrinsic peroxidaselike activity of 2D Fe-BTC. Fig. 4b displays the performance of MIL-100(Fe), 2D Cu(HBTC)-1 and 2D Fe-BTC as peroxidase mimics for catalytic oxidation of TMB by $\mathrm{H}_{2} \mathrm{O}_{2}$. The catalytic activity follows the order of $2 \mathrm{D}$ Fe-BTC $>$ MIL-100(Fe) $>2 \mathrm{D}$ $\mathrm{Cu}$ (HBTC)-1. 2D Fe-BTC exhibits 77 times higher activity than its template $\mathrm{Cu}(\mathrm{HBTC})-1$. In addition, the catalytic activity of 2D Fe-BTC is 2.2 times that of MIL-100(Fe), a well known $3 \mathrm{D}$ crystalline form of iron trimesates. This suggests that 2D nanosheet structure Fe-BTC has a higher density of accessible active sites than 3D bulk MOF crystals. Hence, our result shows that 2D Fe-BTC is an excellent peroxidase-like nanozyme.

2D Fe-BTC displays good storage stability because its catalytic activity was held at $95 \%$ after three-month storage (Fig. S4, $\mathrm{ESI} \dagger$ ). Furthermore, only $4.6 \%$ iron was leached out in $0.2 \mathrm{M}$ 

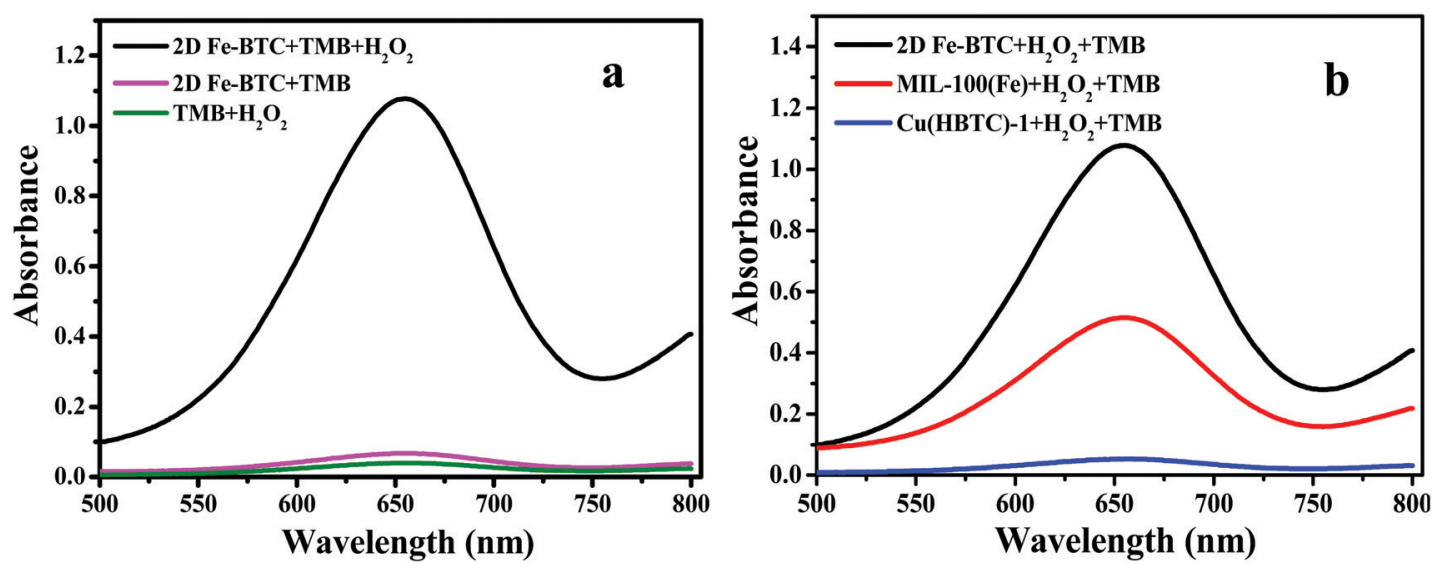

Fig. 4 (a) UV-vis absorption spectra of TMB solutions with and without 2D Fe-BTC in the absence and presence of $\mathrm{H}_{2} \mathrm{O}_{2}$. (b) Catalytic activities of 2D Fe-BTC, $\mathrm{Cu}(\mathrm{HBTC})-1$, and MIL-100(Fe) under the same conditions. Reaction conditions: $0.1 \mathrm{mM} \mathrm{H}_{2} \mathrm{O}_{2}, 0.1 \mathrm{mM} \mathrm{TMB}$, and $10 \mathrm{mg} \mathrm{L} \mathrm{m}^{-1}$ catalyst for $15 \mathrm{~min}$ reaction at $\mathrm{pH} 3.5\left(0.2 \mathrm{M}\right.$ acetate buffer) and $45^{\circ} \mathrm{C}$.

acetate buffer (pH 3.5) (see the ESI $\dagger$ ). In addition, four batches of 2D Fe-BTC synthesized under identical conditions show good reproducibility with less than $2 \%$ variance in the peroxidase-like activity (Table S2, ESI $\dagger$ ). The result suggested the satisfactory storage stability and reproducibility of the $2 \mathrm{D}$ Fe-BTC nanozymes.

\subsection{Kinetic analysis of the $2 D$ Fe-BTC nanozyme}

The Michaelis-Menten kinetic curves of 2D Fe-BTC with a constant TMB concentration and changed $\mathrm{H}_{2} \mathrm{O}_{2}$ concentration or vice versa are illustrated in Fig. 5a and b, respectively. Two apparent kinetic parameters, namely, $K_{\mathrm{m}}$ and $V_{\max }$, for $2 \mathrm{D}$ Fe-BTC were obtained and compared with other 3D Fe-based MOF nanozymes and HRP. As shown in Table 1 , the $K_{\mathrm{m}}$ values of 2D Fe-BTC for TMB and $\mathrm{H}_{2} \mathrm{O}_{2}$ were $0.2610 \mathrm{mM}$ and $0.0334 \mathrm{mM}$, which were 1.6 and 1.9-fold lower than those of 3D MIL-100(Fe), respectively. $K_{\mathrm{m}}$ is an indicator of the affinity of an enzyme for a substrate. In general, a lower $K_{\mathrm{m}}$ value indicates higher affinity between the nanozyme and the substrate, and vice versa. Compared with 3D MIL-100(Fe), 2D Fe-BTC shows better affinity to $\mathrm{H}_{2} \mathrm{O}_{2}$ and TMB due to their nearly half $K_{\mathrm{m}}$ value relative to MIL-100(Fe). In addition, the TMB oxidation rate and $\mathrm{H}_{2} \mathrm{O}_{2}$ reduction rate at a unit mass concentration of catalyst $\left(K_{\mathrm{w}}\right.$, see the ESI $\left.\dagger\right)$ for $2 \mathrm{D}$ Fe-BTC were $2.7-72.3$ and 1.5-37.9 times those of the previously reported 3D Fe-MOF nanozymes, ${ }^{4,5,7,23,24 a}$ respectively. This suggests high catalytic performance of 2D Fe-BTC, which is attributed to the 2D structure of Fe-BTC with rich accessible active sites. Also, the $K_{\mathrm{m}}$ and $V_{\max }$ values of $2 \mathrm{D}$ Fe-BTC for the $\mathrm{H}_{2} \mathrm{O}_{2}$ substrate were 14.6-fold lower and 0.47-fold higher than those of $\mathrm{HRP}^{24 b}$ respectively. This indicated that the $2 \mathrm{D}$ Fe-BTC nanosheets had a stronger affinity and a higher reaction rate for $\mathrm{H}_{2} \mathrm{O}_{2}$ than HRP. Thus, using the 2D Fe-BTC nanozyme may lead to a higher sensitivity for glucose detection than HRP (Table S3, ESI $\dagger)^{24 c}$

The double-reciprocal plots of 2D Fe-BTC are exhibited in Fig. $5 \mathrm{c}$ and $\mathrm{d}$. They were acquired at three $\mathrm{H}_{2} \mathrm{O}_{2}$ concentration levels (0.03 mM, $0.05 \mathrm{mM}$ and $0.08 \mathrm{mM}$ ) and three TMB concentration levels $(0.04 \mathrm{mM}, 0.10 \mathrm{mM}$ and $0.16 \mathrm{mM})$, respectively. As Fig. 5c and d show, the slope of the lines is near parallel, which is the feature of the ping-pong mechanism for substrate oxidation, like the natural enzyme $\mathrm{HRP}^{25 a}$ and other nanoyzmes. ${ }^{24 a, 25 b-d}$ This indicates that 2D Fe-BTC reacts with the first substrate and then sets free the first product before reacting with the second one. ${ }^{25 b-d}$

\subsection{Possible reactive species in the 2D Fe-BTC catalyzed TMB oxidation by $\mathrm{H}_{2} \mathrm{O}_{2}$}

To explore the reactive oxygen types in the $\mathrm{H}_{2} \mathrm{O}_{2} / \mathrm{TMB} / 2 \mathrm{D}$ Fe-BTC system, five radical scavengers were used, including $\mathrm{NaN}_{3}\left({ }^{1} \mathrm{O}_{2}\right.$ quencher), thiourea ( $\mathrm{TH},{ }^{\bullet} \mathrm{OH}$ radical quencher), $p$-benzoquinone (BQ, $\mathrm{O}_{2}{ }^{\bullet-}$ radical quencher), and ascorbic acid (AA, quencher of ${ }^{\bullet} \mathrm{OH}$ and $\mathrm{O}_{2}^{\bullet-}$ radicals). As Fig. S5 (ESI $\dagger$ ) shows, BQ, TH and AA caused an apparent decrease in the $A_{652}$ value of the $\mathrm{H}_{2} \mathrm{O}_{2} / \mathrm{TMB} / 2 \mathrm{D}$ Fe-BTC system, and $A_{652}$ decreased with the scavenger concentration. Thus, ${ }^{\bullet} \mathrm{OH}$ radicals and $\mathrm{O}_{2}{ }^{\bullet-}$ radicals were produced in this system and played an important role in TMB oxidation. The production of ${ }^{\bullet} \mathrm{OH}$ and $\mathrm{O}_{2}{ }^{\bullet-}$ radicals was further confirmed by EPR (electron paramagnetic resonance, see the ESI $\dagger$ ) results. Fig. S6a (ESI $\dagger$ ) displays the enhanced characteristic EPR peaks of the DMPO $/{ }^{\bullet} \mathrm{OH}$ adduct with an intensity ratio of $1: 2: 2: 1$ upon addition of $2 \mathrm{D}$ Fe-BTC into the DMPO/ $\mathrm{H}_{2} \mathrm{O}_{2}$ system, indicating the generation of more - $\mathrm{OH}$ radicals in the presence of 2D Fe-BTC. Similarly, when 2D Fe-BTC aqueous solution was replaced by 2D Fe-BTC methanol solution, the EPR spectrum presents four peaks with almost equal intensity (Fig. S6b, ESI $\dagger$ ), suggesting generation of $\mathrm{O}_{2}{ }^{\bullet-}$ radicals in the reaction system. In addition, the introduction of $\mathrm{NaN}_{3}$ caused a subtle change in $A_{652}$ of the $\mathrm{H}_{2} \mathrm{O}_{2} / \mathrm{TMB} / 2 \mathrm{D}$ FeBTC system (Fig. S5, ESI $\dagger$ ), suggesting that singlet oxygen was not the key reactive species.

\subsection{Optimization of the 2D Fe-BTC nanozyme activity for the determination of $\mathrm{H}_{2} \mathrm{O}_{2}$}

Like other nanozymes, the peroxidase mimic catalytic performance of 2D Fe-BTC was controlled by $\mathrm{pH}$, temperature and its 

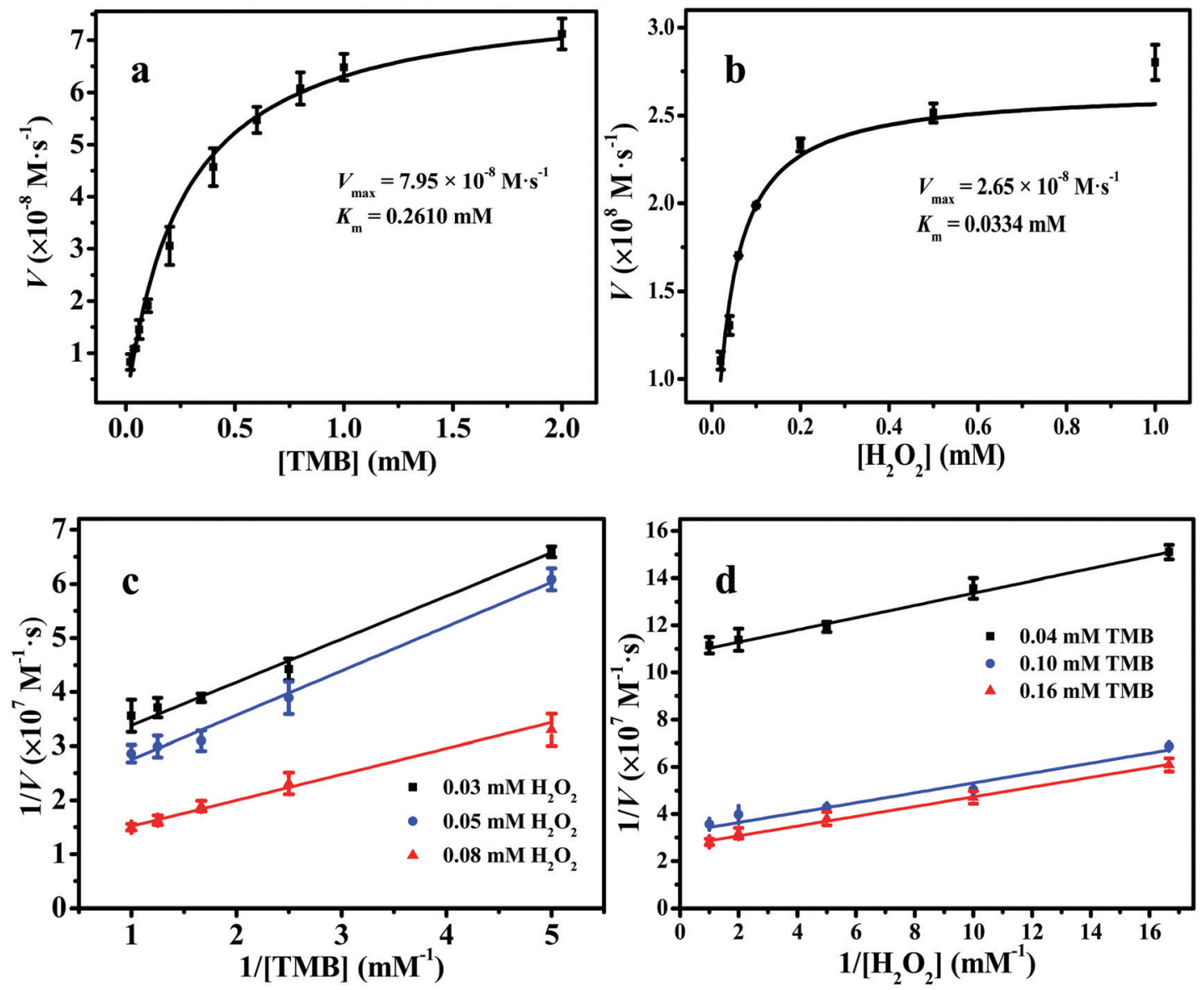

Fig. 5 (a) Steady-state kinetic assay of 2D Fe-BTC at $0.08 \mathrm{mM} \mathrm{H}_{2} \mathrm{O}_{2}$ and different TMB concentrations. (b) Steady-state kinetic assay of 2D Fe-BTC at

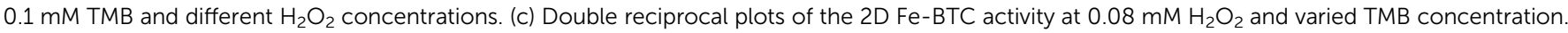
(d) Double reciprocal plots of the 2D Fe-BTC activity at $0.1 \mathrm{mM} \mathrm{TMB}$ and varied $\mathrm{H}_{2} \mathrm{O}_{2}$ concentration.

concentration. Fig. S7a (ESI $\dagger$ ) shows that the catalytic activity of 2D Fe-BTC increased with $\mathrm{pH}$ from 2.5 to 3.5 and decreased with $\mathrm{pH}$ from 3.5 to 9.0. This is likely attributed to the diamine structure of TMB, which has poor solubility at a higher $\mathrm{pH}^{25 e}$ Thus, $\mathrm{pH} 3.5$ was used as the optimal $\mathrm{pH}$ for subsequent experiments. The temperature effect was studied from $20{ }^{\circ} \mathrm{C}$ to $55{ }^{\circ} \mathrm{C}$. Fig. S7b (ESI $\dagger$ ) shows that the catalytic activity reached its peak when the temperature was $45^{\circ} \mathrm{C}$, which was used as the optimum temperature. This is because when the temperature is increased from $20{ }^{\circ} \mathrm{C}$ to $45^{\circ} \mathrm{C}$, the content of $\mathrm{TMB}^{+\bullet}$ (cation freeradical, one-electron oxidation product of $\mathrm{TMB}$, Scheme $\mathrm{S} 1$, see the ESI $\dagger$ ) grows to a maximum, ${ }^{25 f}$ leading to maximal $A_{652}$ (Fig. S7c, ESI $\dagger$ ). Meanwhile, when the temperature is above $45{ }^{\circ} \mathrm{C}$, the peak at $652 \mathrm{~nm}$ decays due to formation of an

Table 1 Comparison of the apparent Michaelis-Menten constant $\left(K_{m}\right)$, maximum reaction rate $\left(V_{\text {max }}\right)$, and rate at unit mass concentration of the catalyst $\left(K_{\mathrm{w}}\right)$ between 2D Fe-BTC and other 3D Fe-MOFs, and HRP

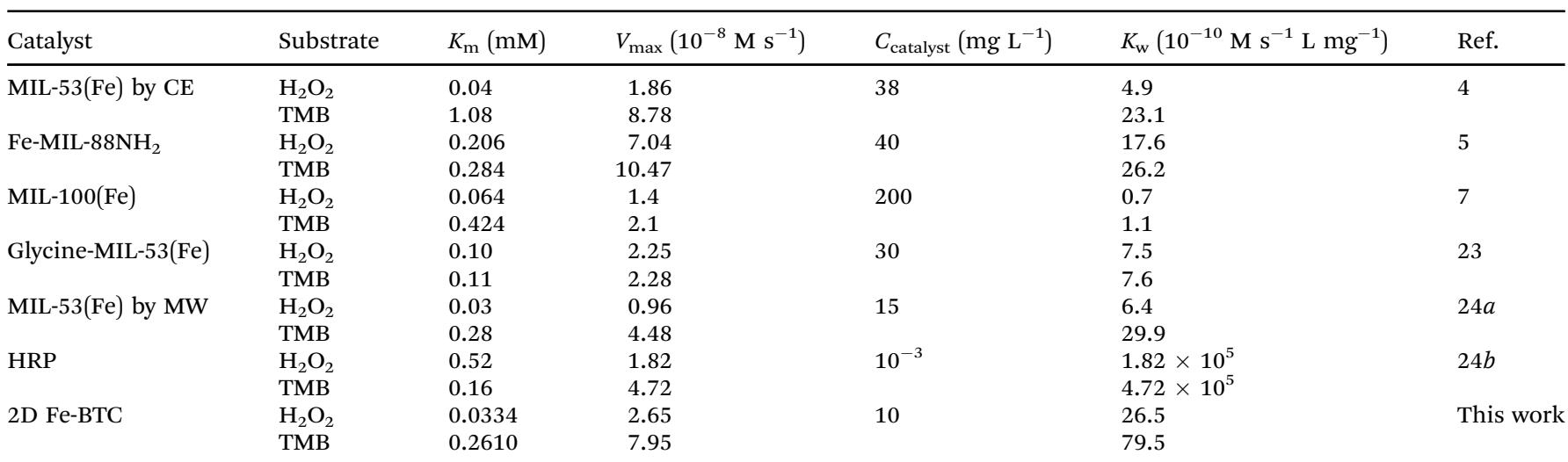



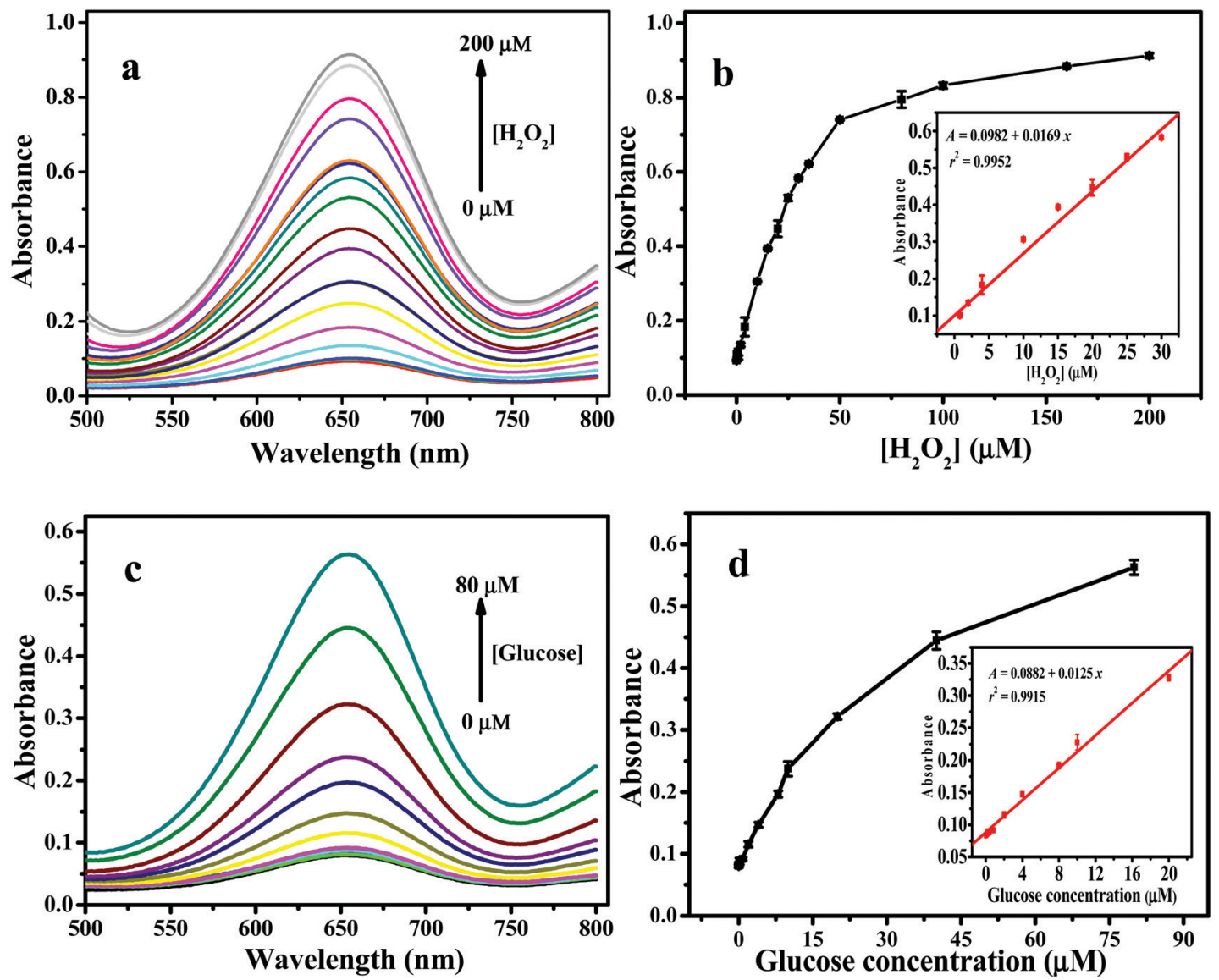

Fig. 6 (a) UV/vis spectra of the TMB/2D Fe-BTC system upon addition of various concentrations of $\mathrm{H}_{2} \mathrm{O}_{2}$. (b) A concentration-response curve for $\mathrm{H}_{2} \mathrm{O}_{2}$. Inset: Linear calibration plot for $\mathrm{H}_{2} \mathrm{O}_{2}$. (c) UV/vis spectra of the TMB/2D Fe-BTC/GODx system upon addition of various concentrations of glucose. (d) A concentration-response curve for glucose. Inset: Linear calibration plot for glucose.

abundant yellow complex of a two-electron oxidation product of TMB (inset in Fig. S7c, ESI $\dagger$ ) with a peak at $450 \mathrm{~nm}$ (Fig. S7c, ESI $\dagger$ ). The effect of the concentration of 2D Fe-BTC was investigated from 2.5 to $35 \mathrm{mg} \mathrm{L}^{-1}$. As displayed in Fig. S7d (ESI $\dagger$ ), the catalytic activity of 2D Fe-BTC increased with the 2D Fe-BTC concentration in the $2.5-10 \mathrm{mg} \mathrm{L}^{-1}$ range, while it decreased slowly at above $10 \mathrm{mg} \mathrm{L}{ }^{-1} 2 \mathrm{D} \mathrm{Fe-BTC.} \mathrm{Based} \mathrm{on} \mathrm{the} \mathrm{above}$ results, the optimal peroxidase-like activity of $2 \mathrm{D}$ Fe-BTC was obtained under the conditions of $\mathrm{pH} 3.5,45^{\circ} \mathrm{C}$ and $10 \mathrm{mg} \mathrm{L}^{-1}$ of 2D Fe-BTC. Fig. 6a shows that the absorbance of the TMB/2D Fe-BTC/ $\mathrm{H}_{2} \mathrm{O}_{2}$ system increases with the $\mathrm{H}_{2} \mathrm{O}_{2}$ concentration up to $200 \mu \mathrm{M}$. Fig. $6 \mathrm{~b}$ shows that the linear range for $\mathrm{H}_{2} \mathrm{O}_{2}$ is 0.04-30 $\mu \mathrm{M}\left(r^{2}=0.9952, n=10\right)$. The limit of detection (LOD, $3 \sigma$ ) for $\mathrm{H}_{2} \mathrm{O}_{2}$ is $36 \mathrm{nM}$, which is much lower than those obtained by other $3 \mathrm{D}$ Fe-MOF and Fe-based nanozymes, including MIL-53(Fe), ${ }^{4}$ MIL-68(Fe), ${ }^{6}$ MIL-100(Fe), ${ }^{7} \mathrm{Fe}_{3} \mathrm{O}_{4} @ M S ~ N P s,{ }^{26}$ $\mathrm{Fe}_{3} \mathrm{O}_{4} @ \mathrm{C}$ nanostructures, ${ }^{27}$ and $\mathrm{Fe}_{3} \mathrm{~S}_{4} \mathrm{MNPs}^{28}$ (Table S3, ESI $\dagger$ ).

\subsection{Application of the 2D Fe-BTC nanozyme for glucose biosensing}

To demonstrate the potential application of the 2D Fe-BTC peroxidase-like nanozyme in biosensing, we constructed a colorimetric assay by coupling glucose oxidase (GODx) with
2D Fe-BTC as peroxidase mimics for detecting glucose in serum because $\mathrm{H}_{2} \mathrm{O}_{2}$ is a glucose oxidation product in the presence of GODx. Following the procedure for construction of the glucose standard curve in the Experimental section (see the ESI $\dagger$ ), the absorbance of the 2D Fe-BTC nanozyme-based color system increases with the glucose concentration up to $80 \mu \mathrm{M}$ (Fig. 6c). A linear response for glucose was obtained over the range of 0.04 to $20 \mu \mathrm{M}\left(r^{2}=0.9915, n=9\right)$ (Fig. 6d). The LOD $(3 \sigma)$ for glucose was $39 \mathrm{nM}$. As shown in Table S3 (ESI $\dagger$ ), the LOD obtained for 2D Fe-BTC for glucose was much lower than those for other 3D Fe-MOFs, such as Fe-MIL-88NH ${ }_{2}{ }^{5}$ and MIL-53(Fe), ${ }^{24}$ and other Fe-based nanozymes, including $\mathrm{Fe}_{3} \mathrm{O}_{4} @ \mathrm{MS} \mathrm{NPs},{ }^{26} \mathrm{Fe}_{3} \mathrm{O}_{4}$ @C nanostructures, ${ }^{27} \mathrm{Fe}_{3} \mathrm{~S}_{4} \mathrm{MNPs},{ }^{28}$ and $\mathrm{Fe}-\mathrm{g}-\mathrm{C}_{3} \mathrm{~N}_{4} \cdot{ }^{29}$ The result indicated high sensitivity of the $2 \mathrm{D}$ Fe-BTC nanozyme based method for glucose.

To verify the specificity of the assay for glucose detection in practical serum samples, selectivity trials were conducted by replacing $0.05 \mathrm{mM}$ glucose with $0.5 \mathrm{mM}$ of lactose, fructose and maltose, respectively. Fig. S8 (ESI $\dagger$ ) shows that these analogues of glucose have a minor response even at 10 times the glucose concentration. This indicates that the 2D Fe-BTC peroxidase mimetic-based colorimetric assay promises high selectivity for glucose detection. Following the experimental details for 
Table 2 The result of glucose determination in human serum samples

\begin{tabular}{lll}
\hline Sample & $\begin{array}{l}\text { 2D Fe-BTC based } \\
\text { assay }^{a}(\mathrm{mM}, n=3)\end{array}$ & $\begin{array}{l}\text { GODx-PAP } \\
\text { assay }(\mathrm{mM})\end{array}$ \\
\hline Serum 1 & $5.17 \pm 0.05$ & 5.1 \\
Serum 2 & $5.74 \pm 0.12$ & 6.0 \\
Serum 3 & $3.51 \pm 0.09$ & 3.9 \\
${ }^{a}$ Mean \pm standard deviation $(n=3)$. &
\end{tabular}

glucose detection in real samples in the Experimental section (see the ESI $\dagger$ ), the method was used for glucose determination in three human serum samples. Table 2 shows that the result obtained from this method is consistent with that from a commercial glucose GODx-PAP assay. This demonstrates high accuracy and reliability of the assay for glucose detection in complex samples.

\section{Conclusion}

In conclusion, via a multivalent cation substitution strategy, we successfully prepared 2D Fe-BTC with high peroxidase mimetic activity. The $\mathrm{Cu}$ (HBTC)-1 nanosheet was used as a precursor to synthesize 2D Fe-BTC at room temperature. 2D Fe-BTC shows much higher affinity to $\mathrm{H}_{2} \mathrm{O}_{2}$ and TMB relative to other 3D Fe-based MOFs. The enhanced catalytic activity is mainly attributed to highly accessible active sites on the surface of 2D Fe-BTC, which is beneficial for the contact of substrate molecules with the catalyst during TMB oxidation by $\mathrm{H}_{2} \mathrm{O}_{2}$. The major reactive oxygen types in the $\mathrm{H}_{2} \mathrm{O}_{2} / \mathrm{TMB} / 2 \mathrm{D}$ Fe-BTC system are ${ }^{\bullet} \mathrm{OH}$ radicals and $\mathrm{O}_{2}{ }^{\bullet-}$ radicals. Based on the excellent peroxidase-like activity of 2D Fe-BTC, a simple, sensitive and selective platform was constructed to determine $\mathrm{H}_{2} \mathrm{O}_{2}$ and glucose. The assay was satisfactorily utilized for glucose determination in complex matrices, such as human serum samples. Our work reveals a prospective strategy for the rational design of 2D MOF nanozymes for chemo/biosensing applications.

\section{Conflicts of interest}

There are no conflicts to declare.

\section{Acknowledgements}

This work is financially supported by the Fundamental Research Funds for the Central Universities (XDJK2019C030).

\section{References}

1 R. J. Kuppler, D. J. Timmons, Q. Fang, J. Li, T. A. Makal, M. D. Young, D. Yuan, D. Zhao, W. Zhuang and H. Zhou, Coord. Chem. Rev., 2009, 253, 3042-3066.

2 D. Feng, Z. Gu, J. Li, H. Jiang, Z. Wei and H. Zhou, Angew. Chem., Int. Ed., 2012, 51, 10307-10310.

3 (a) Y. Chen, T. Hoang and S. Ma, Inorg. Chem., 2012, 51, 12600-12602; (b) S. Li, X. Liu, H. Chai and Y. Huang,
TrAC, Trends Anal. Chem., 2018, 105, 391-403; (c) S. Li, X. Hu, Q. Chen, X. Zhang, H. Chai and Y. Huang, Biosens. Bioelectron., 2019, 137, 133-139.

4 L. Ai, L. Li, C. Zhang, J. Fu and J. Jiang, Chem. - Eur. J., 2013, 19, 15105-15108.

5 Y. Liu, X. J. Zhao, X. X. Yang and Y. F. Li, Analyst, 2013, 138, 4526-4531.

6 J. W. Zhang, H. T. Zhang, Z. Y. Du, X. Q. Wang, S. H. Yu and H. L. Jiang, Chem. Commun., 2014, 50, 1092-1094.

7 A. H. Valekar, B. S. Batule, M. I. Kim, K. Cho, D. Hong, U. Lee, J. Chang, H. Park and Y. K. Hwang, Biosens. Bioelectron., 2018, 100, 161-168.

8 M. Zhao, Q. Lu, Q. Ma and H. Zhang, Small Methods, 2017, 1, 1600030.

9 D. Deng, K. S. Novoselov, Q. Fu, N. Zheng, Z. Tian and X. Bao, Nat. Nanotechnol., 2016, 11, 218-230.

10 (a) M. T. Zhao, Y. Huang, Y. W. Peng, Z. Q. Huang, Q. L. Ma and H. Zhang, Chem. Soc. Rev., 2018, 47, 6267-6295; (b) Y. Sun, S. Gao, F. Lei and Y. Xie, Chem. Soc. Rev., 2015, 44, 623-636.

11 (a) X. Q. Liu, Z. Q. Yan, Y. Zhang, Z. W. Liu, Y. H. Sun, J. S. Ren and X. G. Qu, ACS Nano, 2019, 13, 5222-5230; (b) F. Cao, M. Zhao, Y. Yu, B. Chen, Y. Huang, J. Yang, X. Cao, Q. Lu, X. Zhang, Z. Zhang, C. Tan and H. Zhang, J. Am. Chem. Soc., 2016, 138, 6924-6927.

12 Y. Wang, M. Zhao, J. Ping, B. Chen, X. Cao, Y. Huang, C. Tan, Q. Ma, S. Wu, Y. Yu, Q. Lu, J. Chen, W. Zhao, Y. Ying and H. Zhang, Adv. Mater., 2016, 28, 4149-4155.

13 Y. Peng, Y. Li, Y. Ban, H. Jin, W. Jiao, X. Liu and W. Yang, Science, 2014, 346, 1356-1359.

14 P. Li, Y. Maeda and Q. Xu, Chem. Commun., 2011, 47, 8436-8438.

15 T. Rodenas, I. Luz, G. Prieto, B. Seoane, H. Miro, A. Corma, F. Kapteijn, F. X. L i. Xamena and J. Gascon, Nat. Mater., 2015, 14, 48-55.

16 (a) L. Qin, X. Wang, Y. Liu and H. Wei, Anal. Chem., 2018, 90, 9983-9989; (b) X. Wang, X. Jiang and H. Wei, J. Mater. Chem. B, 2020, 8, 6905-6911.

17 W. Li, Y. Zhang, C. Zhang, Q. Meng, Z. Xu, P. Su, Q. Li, C. Shen, Z. Fan, L. Qin and G. Zhang, Nat. Commun., 2016, 7, 11315.

18 (a) G. Zhan and H. C. Zeng, Adv. Fun. Mater., 2016, 26, 3268-3281; (b) W. H. Niu, L. G. Li, X. J. Liu, N. Wang, J. Liu, W. J. Zhou, Z. H. Tang and S. W. Chen, J. Am. Chem. Soc., 2015, 137, 5555-5562.

19 M. Sanchezsanchez, I. De Asua, D. Ruano and K. Diazl, Cryst. Growth Des., 2015, 15, 4498-4506.

20 J. B. Decoste, G. W. Peterson, B. J. Schindler, K. L. Killops, M. A. Broweb and J. J. Mahle, J. Mater. Chem. A, 2013, 1, 11922-11932.

21 R. Kaur, A. Kaur, A. Umar, W. A. Andersonc and S. K. Kansal, Mater. Res. Bull., 2019, 109, 124-133.

22 N. M. Mahmoodi, J. Abdi, M. Oveisi, M. A. Asli and M. Vossoughi, Mater. Res. Bull., 2018, 100, 357-366.

23 W. Dong, L. Yang and Y. Huang, Talanta, 2017, 167, 359-366.

24 (a) W. Dong, X. Liu, W. Shi and Y. Huang, RSC Adv. , 2015, 5, 17451-17457; (b) L. Liu, Y. Shi, Y. Yang, M. Li, Y. Long, Y. Huang and H. Zheng, Chem. Commun., 2016, 52, 
13912-13915; (c) S. Xu, H. Qi, S. Zhou, X. Zhang and C. Zhang, Microchim. Acta, 2014, 181, 535-541.

25 (a) D. J. T. Porter and H. J. Brights, J. Bio. Chem., 1983, 258, 9913-9924; (b) Y. L. Dong, H. G. Zhang, Z. U. Rahman, L. Su, X. J. Chen, J. Hu and X. G. Chen, Nanoscale, 2012, 4, 3969-3976; (c) L. Z. Gao, J. Zhuang, L. Nie, J. B. Zhang; Y. Zhang, N. Gu, T. Wang, J. Feng, D. Yang and S. Perrett, Nat. Nanotechnol., 2007, 2, 577-583; (d) A. Ahmed, P. John, M. H. Nawaz, A. Hayat and M. Nasir, ACS App. Nano Mater., 2019, 2, 5156-5168; (e) W. He, Y. Liu, J. Yuan, J.-J. Yin, X. Wu, X. Hu, K. Zhang, J. Liu, C. Chen, Y. Ji and Y. Guo,
Biomaterials, 2011, 32, 1139-1147; $(f)$ J. Yin, H. Cao and Y. Lu, J. Mater. Chem., 2012, 22, 527-534.

26 Y. Wang, B. Zhou, S. Wu, K. Wang and X. He, Talanta, 2015, 134, 712-717.

27 N. Lu, M. Zhang, L. Ding, J. Zheng, C. Zeng, Y. Wen, G. Liu, A. Aldalbahi, J. Shi, S. Song, X. Zuo and L. Wang, Nanoscale, 2017, 9, 4508-4515.

28 C. Ding, Y. Yan, D. Xiang, C. Zhang and Y. Xian, Microchim. Acta, 2016, 183, 625-631.

29 J. Tian, Q. Liu, A. M. Asiri, A. H. Qusti, A. O. Al-Youbi and X. Sun, Nanoscale, 2013, 5, 11604-11609. 